\title{
First-time mothers' expectations of public health nurses in Finland
}

Marja-Terttu Tarkka, Kristiina Lehti, Marja Kaunonen, Päivi Åstedt-Kurki and Marita Paunonen-IImonen, Department of Nursing Science, University of Tampere, Finland

\begin{abstract}
The purpose of this explorative study was to ascertain what kind of guidance and support first-time mothers expected from public health nurses (PHN) at child welfare clinics, while they were still on the maternity ward after delivery. Data were collected by an open-ended question as part of a questionnaire between January and May 1995. The sample comprised 219 mothers. Content analysis was applied. Mothers' expectations focused both on the content of support and on the mode of interaction. Mothers expected that issues concerning mainly the child, but also the mother, and the whole family would be discussed at the child welfare clinic. Mothers expected to receive advice and instruction on childcare, that interaction would be individual and family-centred in nature, and that the care would be continuous. Mothers hoped that the atmosphere of interaction would be safe, confidential, peaceful and encouraging. $\mathrm{PHNs}$ were expected to have not only professional skill, that is, knowledge and competence, but also a friendly, empathic attitude and a sense of humour. Mothers' expectations of the PHN varied greatly, so the support provided by the PHN should be based on charting the family's need for support, not on routine guidance and counselling. Further research should focus on how the family's need for support changes during the child's first year of life.
\end{abstract}

Key words: first-time mothers; mothers' expectations; public health nurses

\section{Introduction}

The first months after childbirth are a trying time for the first-time mother. Apart from pregnancy and delivery, the mother experiences the greatest changes in the process of parenthood over a period of 3 months after delivery. Karila $(1988 ; 1989)$ found that the most difficult period for women in their growth into parenthood was precisely this postpartum period. Particularly first-time mothers may worry and feel anxious about breast feeding and about how they will cope with childcare. In order to cope, the mother needs to identify the needs of her child and assess how she can solve different situations.

Social support is central to coping with change (Cohen and Syme, 1985; Payne and Jones, 1987;

Address for correspondence: Marja-Terttu Tarkka, Department of Nursing Science, University of Tampere, FIN-33014, Finland.
Turner, 1983). To identify important significant others, such as the child's father, can help in the process of motherhood (Higgins et al., 1993; Mercer, 1986; Tarkka and Paunonen, 1996; Ventura, 1986). Social support has been found to enhance the mother's self-confidence and assurance in her role as a mother. Encouragement, supporting the mother's decision-making, as well as concrete forms of support have been shown to ease the mother's stress, thereby increasing her satisfaction (Crockenberg and McCuskay, 1986; Dakof and Taylor, 1990). Whether a mother wants advice, support and assistance mainly from family members, relatives, friends, neighbours or from professionals, varies from mother to mother (Pridham, 1984; 1987). Particularly in the early stages of motherhood, mothers seek professional help to cope with their new task as a mother (Pridham and Chang, 1992). Younger mothers have also been found to seek expert advice more often than compared with more experienced mothers (Pridham et al., 1982). 
Maternal and child health care holds a special position in Finnish health care. In 1945, legal obligation was imposed on local authorities to provide maternity and child welfare services. Since 1972, in keeping with the Primary Health Care Act of 1972, the services of maternity and child welfare clinics are provided under the community health centre organization. These services have always been free of charge. PHNs have played a key role in running the child health care system. For the first 6 months, the family or at least the mother and her child, visits the child welfare clinic approximately once a month and during the week it is always possible to contact the PHN by telephone. In many communities the PHN's work is implemented based on the population responsibility principle. It means that the same PHN works with the pregnant mother and with the family after the baby is born. In practice, the participation of families in the health centre activity is $100 \%$ in time of data collection, especially in the group with children under 1 year of age (Suomen Tilastollinen Vuosikirja, 1995).

Recent studies have described clients' conceptions of child welfare clinics' services. Although families have been relatively satisfied with the services (Jansson et al., 1998; Viljanen, 1993; Viljanen and Lauri, 1990), critique, expectations and demands have clearly increased during the past years (Pelkonen, 1994; Rautava, 1989; Viljanen, 1993). Both the content of action and the clientPHN interaction have come under criticism. The clinics have been criticized particularly for concentrating too much on the child's physical health, whereas parents would want more support in questions concerning upbringing and parental skills. Families have also hoped for unhurried interaction and more individual-level services.

Although studies of child welfare clinics have been reported, there is little research-based knowledge of the nature of the support expected by firsttime mothers from the PHN at the child welfare clinic. Research suggests that first-time mothers feel that their ability to cope with childcare is worse compared with mothers having given birth previously, but the difference disappears as soon as the mother becomes more experienced in childcare (Pridham and Chang, 1992). The studies made have usually covered the entire clientele of the child welfare clinics, that is, 0-6-year-old children and their families (e.g., Pelkonen, 1994; Viljanen and Lauri, 1990). No research-based knowledge is available about what mothers expect from the PHN at the child welfare clinic in the early stages of motherhood, when the child is a few days old and the mother is most inexperienced and the need for support is at its height. The purpose of this explorative study was to ascertain what kind of expectations the first-time mothers, who were still on the maternity ward after childbirth have from the PHN at the child welfare clinic. The research question was: 'What kind of guidance and support mothers expect from the PHN as a first-time mother'.

\section{Methods}

\section{Data collection}

Data were collected by one open-ended question as part of a questionnaire, which contained large number of structure and three open-ended questions. The questionnaire was distributed to all first-time mothers $(n=329)$ at a Finnish university hospital from January to May in 1995. Three criteria were applied in recruitment, i.e., vaginal delivery, single-embryo pregnancy, and the newborn infant was not in intensive care. Respondents completed the questionnaire before hospital discharge and returned it in a closed envelope to the ward office. Altogether $271 \quad(82 \%)$ mothers returned the questionnaire, $219(81 \%)$ of whom responded to the open-ended question.

\section{Sample}

The mean age of the participants was 28 years, range 17-42 years. Altogether, $94 \%$ of the mothers were living in a pair relationship. More than half of them $(66 \%)$ had either an academic or college level degree and about half $(55 \%)$ had worked outside the home before the birth of the child.

\section{Data analysis}

The open-ended question was analysed using content analysis. First, the answers were read through several times to acquire an overall picture of the answers. A statement was chosen to be the unit of analysis. A statement is an expression involving a few words, which describes the phenomenon defined in the research assignment and comprises one meaning. Some answers contained only one statement, but the majority contained two 
to four statements. In the next stage, the statements discovered were marked in the margin of the page, and a list was composed of them. Similarities and differences between the statements were then examined. Statements of similar content were integrated into the same category and a name describing its content was given to the category. Analysis continued by combining the categories of similar content by forming upper categories from them. The upper categories were given names, which described those subcategories from which they were formed. Abstraction continued by forming aggregate categories from the upper categories (Figure 1) (Burnard, 1991; Downe-Wamboldt, 1992; Polit and Hungler, 1999).

\section{Results}

Mothers' expectations of the PHN pertained to both the content and mode of interaction. The content of interaction is described by the category of family development, which contains extensive issues related especially to the child, but also to the mother and family (Figure 2). The mode of interaction is described by the aggregate category of expectations of interaction, which comprises four subcategories: philosophy of nursing, implication of nursing practice, atmosphere of the relationship and characteristics of the PHN (Figure 3).

\section{Growth into motherhood}

Pregnancy and childbirth experiences were still very strong in mothers' mind when they participated in the study. The mothers also described that counselling during pregnancy should provide information on the changes taking place in the woman's body, on pregnancy-related examinations and procedures and surveillance of the progress of pregnancy. Participants hoped to receive information about the course of delivery, alternative modes of delivery and pain relief. They also wanted an opportunity to review their experiences of delivery and childbirth at the child welfare clinic. They also wanted to be informed of postnatal depression. Additionally, mothers wanted guidance in the early stages of motherhood, for example, on breast feeding:

Most of all, about how to feed the child. What if my breasts dry up ... (68)

Lots of advice on breast feeding, for how long, inconvenience caused by a breast pump? (75)
2. Clear, concrete instructions on childcare. Information about what problems the family might experience after childbirth, that is, how the birth of a child affects the pair relationship. Information on commonest childhood diseases and ailments and care instruction on how to treat these.

102. Support for everyday life. To be able to telephone and ask even the simplest questions in an emergency, time for discussions and questions during the visit. 235. Information about when the wound heals. Reassurance that I' $m$ definitely the best mom in the world. After all, I delivered a son!
- clear instructions

concrete instructions

- instructions on childcare

- information about how the birth of a child affects

- information about commonest childhood diseases

- instructions on how to treat these

- support for everyday life

- to be able to phone and ask even simple questions

- time for discussions and questions

- information about when the wound heals

- reassurance that I'm the world's best mom

2. Formation of the system of categories

\begin{tabular}{|llll|}
\hline & Category & Upper category & Aggregate category \\
- clear instructions & Professionalism & Characteristics of PHN & Expectations of interaction \\
- concrete advice & Concrete guidance & Implication of nursing practice & Expectations of interaction \\
- advice on childcare & Childcare & Knowing childhood & Family development \\
- information about how the child affects pair relationship & Pair relationship & Changes in family & Family development \\
- information about childhood illnesses & Child's illnesses & Knowing childhood & Family development \\
- instruction on how to treat these & Child's illnesses & Knowing childhood & Family development \\
- support for everyday life & Childcare & Knowing childhood & Family development \\
- to be able to phone and ask simple questions & Confidentiality & Atmosphere of interaction & Expectations of interaction \\
- time for discussion and questions & Peacefulness & Atmosphere of interaction & Expectations of interaction \\
- information about when the wound heals & Health counselling & Implication of nursing practice & Expectations of interaction \\
- reassurance that I'm the world's best mom & Encouragement & Atmosphere of interaction & Expectations of interaction \\
\hline
\end{tabular}

Figure 1 Example of the analysis of open-ended question 


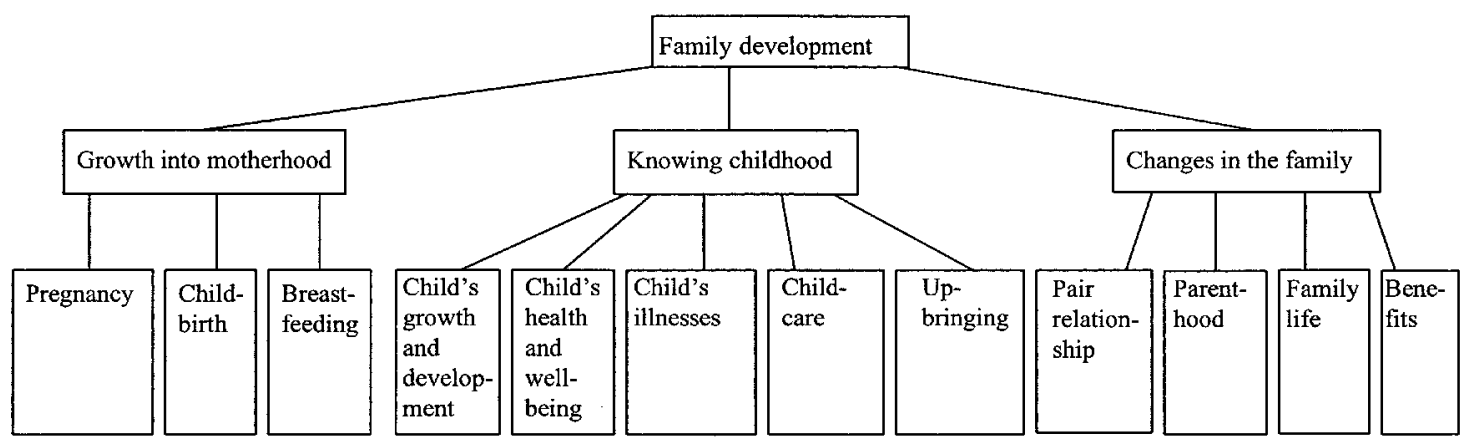

Figure 2 Categories of the support expected by mothers

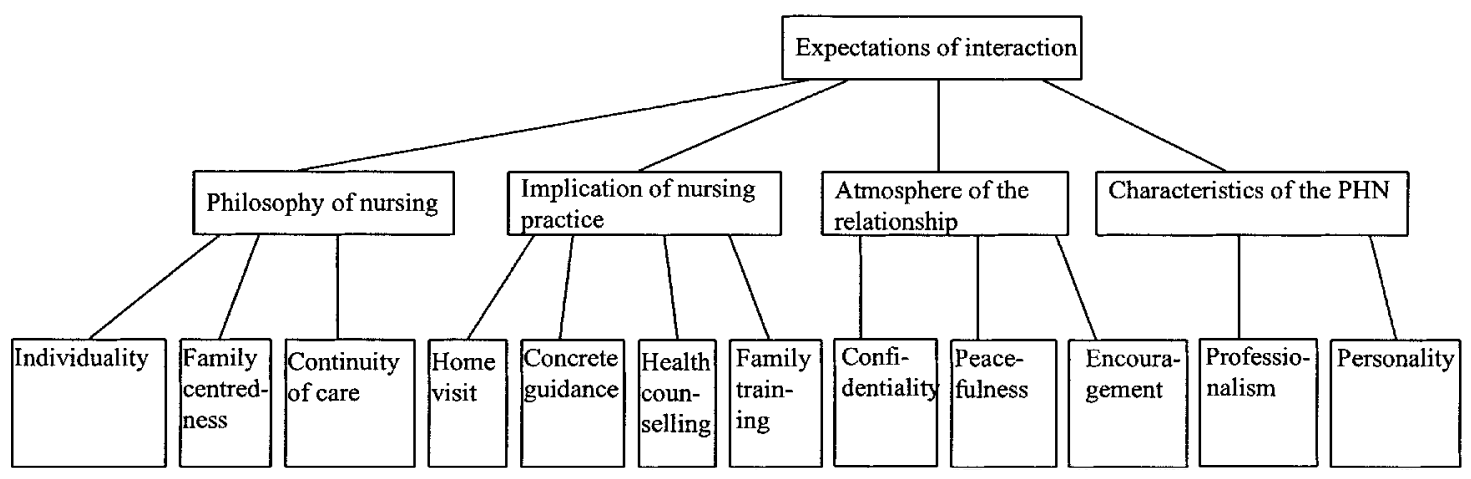

Figure 3 Categories of the mode of support expected by mothers

Advice on every possible prospective problem: what to do if breast feeding is difficult due to a shortage of breast milk? (98)

\section{Knowing childhood}

Mothers expected the PHN to follow-up and inform them of the infant's growth, development and health. Apart from giving information about the different stages of life and development, the PHN was expected to query the mother's opinion of the child's development. Mothers also wanted information, guidance and support on upbringing and advance information on the most common childhood diseases and advice and instruction on how to care for a sick child. They also wanted information about immunizations and hints about how to treat the child's wind pains. Most of all, mothers expected to receive advice and instruction on basic childcare, but also hints on 'good oldfashioned methods'. Part of the statements expressed a general wish to receive instruction on childcare, whereas others had specified the questions on which they wanted instruction and advice:

How to start giving solid food? (63)

Advice on bathing, hints about how to interpret the baby's cry, how to satisfy and dress the child (clothing), outdoor activities and travelling with the child (156)

Hints regarding sleep disorders, etc. (187)

Guidance on childcare; lifting, basic procedures. . . (327)

\section{Changes in the family}

Mothers expected that the PHN would inform them about the changes in family-life and pairrelationship brought about by the child:

She should inform us about how crises, etc., affect our relationship and how to cope with them (158)

Feeding, outdoor activities and changing nappies are easier to cope with than the 
change in the family, especially with the first child (257)

Mothers also wanted discussions, support and guidance on parenting skills. The PHN should also inform the family of the benefits they are entitled to after the child is born.

\section{Philosophy of nursing}

Mothers expected the child welfare clinic to work in an individual manner, based on the needs of mother and child. Individuality referred to paying attention to both the mother and child:

I need individual advice, not conveyor-belt counselling (3)

The nurse should chart the mother's needs and knowledge base individually. Individual support for everyday life (7)

Paying attention to the child as an individual, not as points on the growth curve (170)

In the statements, family-centredness indicated paying attention to the family as a whole. Mothers wished that the clinic would pay more attention to fathers and that they should be involved in counselling:

It's not just the mother and child, there's the father too, the entire family unit (51)

Paying attention to and involving fathers (129)

To inform the father about his important role in the family (158)

The father should also receive guidance on childcare (258)

The third principle of care that emerged was the continuity of care. Mothers criticized the maternity clinic for having a high turnover of PHNs and doctors. They also hoped that the advice given at the clinic would be consistent in nature.

\section{Implication of nursing practice}

Mothers hoped that the PHN would make home visits. This would give the opportunity to receive concrete guidance on childcare. Some of the statements constituted general wishes to receive concrete guidance, but some contained detailed accounts of the matters on which concrete guidance was needed. These included bathing, care of navel, how to clip the child's nails, lifting and handling the baby and basic childcare. Some mothers wanted guidance that would be more thorough:

I expect them to show everything step by step if that is what I want (212)

Advice from A to $\mathrm{Z}$ (255)

Practical advice on how to bathe, carry the baby etc., a hundred times if necessary (272)

Mothers wanted to receive health counselling in order to look after themselves. They wanted instructions about how to maintain their own health, and information and advice on wound care. Statements concerning family training usually referred to antenatal training. Mother also wanted postnatal family training, which would deal with the organization of the christening party, insurance issues and the services available for an infant.

\section{Atmosphere of the relationship}

Confidentiality was manifested in two different ways. On the one hand, mothers considered it important to know who to contact when necessary and, on the other hand, that it was easy to contact the child welfare clinic. These factors provided them with a feeling of security. They hoped that the atmosphere at the child welfare clinic would be peaceful. Mothers wanted the PHN to have time for questions and discussions:

Time for discussions during the visit (102)

Time for questions which may seem silly but are new to me (111)

Individual guidance and time, no impersonal lectures (201)

Time, time and once again TIME (272)

The third factor related to the atmosphere was encouragement. Some of the mothers expected encouragement at a general level. On the other hand, mothers had described a great variety of issues in which they needed encouragement, such as motherhood, childcare, breast feeding, decisionmaking and possible crises. Mothers also wanted the PHN to encourage them to pose questions and to speak about their feelings:

To reassure me that I'm a good mother (13) Support for my own thoughts: I don't want the clinic to dictate how I should take care of my baby (21)

To encourage to speak about feelings, hopes and fears (94) 
They should encourage us to ask questions (138)

Encouragement so as to be able to cope (159) Psychological support to be able to cope with possible crises (210)

\section{Characteristics of the PHN}

The statements describing the PHN's characteristics can be classified into two groups: professionalism and personality. It was considered important that the PHN is skilled and knowledgeable, but his/her personality also mattered. Professionalism indicated readiness to answer questions and provide expert advice. Expectations of counselling varied: the advice and answers should be truthful and the information should be up-to-date, clear and comprehensible. Mothers wished that the PHN would inform them about the different ways of dealing with a matter, which would allow the mother to choose the way that is convenient for her. Mothers also expected to receive advice without having to ask questions:

Reasonable, not exaggerated advice on childcare (35)

To discuss my positive feelings about the baby (51)

Guidance according to current information (97)

Unprompted feedback, now I feel I have to know what to ask (191)

Advice on how to manage unexpected situations (200)

Solid information and advice which is to the point (314)

Exhaustive answers to all my troubling questions (323)

Besides professional knowledge and skill, mothers emphasized the importance of the PHN's personality. The nurse was expected to be friendly and to have a sense of humour. Empathy, an understanding attitude towards the mother, was also expected. Mothers particularly pointed out that the PHN should sympathize with the new mother's uncertainty and ignorance.

\section{Discussion}

\section{Validity and reliability of the study}

The voluntary and ample (82\%) participation of the mothers signified that the mothers felt mot- ivated to participate in the study. Moreover, mothers were meticulous in their completion of the questions, since $81 \%$ of mothers who returned the questionnaire responded to the open-ended question. The data analysed represent $67 \%$ of all first-time mothers to whom the questionnaire was distributed. However, nonrespondents cannot be said to have distorted the research findings, since the age, marital status, education and socio-economic position of those who responded to the openended question were not different from the nonrespondents.

The data for this study consisted of one openended question, which was analysed using content analysis. The most important requirement for the reliability of content analysis is correspondence between the original material and the categories generated (e.g., Hickey and Kipping, 1996). To improve the reliability of the analysis, the data were classified by three (M-T.T., K.L., M.K.) independent researchers. Following the comparison of categories and discussions, the final decision on the categories was made with the correspondence between the categories generated and the data in mind. An example of the analysis is offered in order for the reader to be able to follow its progress and to describe the categories generated. Excerpts were reproduced from the respondents' statements. This provides the readers with an opportunity to conclude how well the researchers succeeded in their solutions.

\section{Extensive support}

Two aggregate categories were formed from mothers' expectations: family development and expectations of interaction. Family development depicts the content of support expected, whereas expectations of interaction depict the nature of interaction.

Mothers expected the PHN to tackle issues concerning the mother and the whole family. Earlier research (Pelkonen, 1994; Rautava, 1989; Viljanen, 1993) has shown that child welfare clinics still concentrate on the child's physical development and basic care, whereas issues relating to the entire family and upbringing are rarely touched. However, this study suggests that mothers expect support and concrete guidance especially on childcare. Tarkka's study (1996) showed that $4 \%$ of the mothers had obtained little concrete guidance on childcare and about 
half $(56 \%)$ of mothers were shown little, or not at all, how to care for their baby by the time the child was 3 months old. Thus guidance on welfare clinics is general by nature, whereas mothers expect very concrete guidance on childcare, which is possible for example at PHN's home visit. Reassurance provided by the child welfare clinic that the child was normal in terms of growth and development was found to be important. The child grows and develops rapidly during the first year of life and therefore close observation is essential. Mothers also wanted to receive information on the most common childhood diseases and worried about their coping if the child fell ill. Most of the contacts with the clinic outside appointed visits were caused by the child's illnesses (Viljanen and Lauri, 1990). Mothers wanted the PHN to provide not only information and advice, but also to ask the mother's opinion about the child. Consequently, they wanted to be equal in the interaction between themselves and the PHN. For example, Kuronen (1993), in her qualitative study, has criticized PHNs at child welfare clinic about professionalism and biased guidance.

In the early stages of motherhood, mothers expected to receive support in matters relating to delivery and breast feeding. The possibility of reviewing their experiences of the delivery with the PHN was found to be important. Mothers expect support and concrete guidance on breast feeding. The support and guidance on breast feeding provided by nurses on the maternity ward has a clear association with coping with breast feeding (Freed et al., 1991; Tarkka et al., 1998). However, according to the findings of Tarkka et al. (1999), 37\% of the mothers reported that they had obtained very little or no breast feeding guidance from the public health nurse at the clinic. Succeeding in breast feeding the child is considered one of the central criteria for succeeding in motherhood (Tarkka et al., 1999), so the mother needs all possible support in order to cope with breast feeding.

Mothers wished that they could also discuss changes in family life at the child welfare clinic after the child is born. The birth of the first child is an important phase in the family life cycle. Transition from one stage to another in family life brings about changes in the family's structure, activities and life situation (Hakulinen, 1998; Pridham and Chang, 1992; Wilson et al., 1994).

\section{Interaction}

Mothers expected the interaction with the PHN to be individual, family-centred and continuous. They wanted the atmosphere of interaction to be safe, confidential, unhurried and encouraging. However, according to earlier research, mothers' expectations had not been fully realized. About $80 \%$ of the mothers were satisfied with the calmness and individuality of interaction (e.g., Pelkonen, 1994; Tarkka, 1996). In Tarkka's study (1996), $70 \%$ of the mothers experienced interaction with the PHN to be confidential and in Pelkonen's study (1994), 60\% of the mothers experienced an atmosphere where she was able to talk about sensitive and difficult issues at the child welfare clinic. About a third of the mothers reported that they had had no, or only little, positive feedback from the PHN (Tarkka, 1996). Apart from professional skill, that is, knowledge and competence, the PHN was expected to have a friendly attitude, empathy and a sense of humour. Earlier research on client-nurse interaction has also shown the importance of the nurse's personality. A friendly, positive and skilful PHN enables satisfactory interaction. Confidentiality, equality and continuity are also characteristic of good interaction (e.g., Jansson et al., 1998; Kasch, 1989; Paavilainen and Åstedt-Kurki, 1997a; Viljanen, 1993). Apart from the child, child welfare clinics have traditionally sought to pay attention to the family as well. A family-centred approach has been considered one of the guidelines of the action. Family-centredness is being emphasized, especially while there is a need to underline the quality of care. No research-based knowledge of the realization of family-centredness at child welfare clinics is available. Several studies have referred to the need to develop the action in a more family-centred direction (e.g., Hillan, 1992; Paavilainen and Åstedt-Kurki, 1997b; VehviläinenJulkunen, 1990).

As for the implementation of nursing care, there emerged a need for the PHN's home visits. Other studies have also shown that both parents and PHNs consider home visits necessary (Jansson et al., 1998; Lohiniva, 1999; Vehviläinen-Julkunen, 1995). In a Swedish study (Jansson et al., 1998), PHNs appreciate the first home visit especially as an approach that provides the opportunity to create a good, personal and long-term relationship with the family. Instead in their study mothers saw the meaning of the home visit from a more practical 
point of view and considered personal encounters in a relaxed peaceful atmosphere the most important thing. Despite the fact that PHNs and parents considered home visits important, in the 1990s the number of home visits after delivery has fallen from 98 to $89 \%$ in Finland (Perälä et al., 1998).

Mothers especially hoped for concrete guidance and counselling on childcare and breast feeding. The child welfare clinic tends to concentrate on the child, although the mother's well-being and coping are of primary importance to the well-being of the child. The mothers participating in this study showed interest in their own health and wanted the PHN to provide them with advice on how to look after their own health and fitness.

\section{Development ideas for public health nursing}

The research findings suggest that the PHN should chart the families' needs for support better and act based on these needs. To be able to develop family-centredness, child welfare clinics' action should be reformed in such a way that the fathers and the whole family would also have the opportunity to discuss their concerns at the clinic if they so wished. These study results indicate that firsttime mothers have a great need for professional guidance and support. It is important to develop group training for families after childbirth, where peer support and support from the PHN would be possible. In addition, booklets and other written information should be developed further. Internet services for young families, could be a new possibility to the interaction between the family and the PHN.

This study constituted an initial exploration of what kind of post-partum guidance and support first-time mothers expected from a PHN at a child welfare clinic. A further study will explore how the family's need for support changes during the child's first year of life. The need for support will be determined on two occasions, that is, when the child is 3 and 8 months old.

\section{References}

Burnard, P. 1991: A method of analysing interview transcripts in qualitative research. Nurse Education Today 11, 461-6.

Cohen, S. and Syme, S.L. 1985: Social support and health. London: Academic Press.
Crockenberg, S. and McCluskey, K. 1986: Change in maternal behavior during the baby's first year of life. Child Development 57, 746-53.

Dakof, G.A. and Taylor, S.E. 1990: Victims' perceptions of social support: What is helpful from whom? Journal of Personality and Social Psychology 58, 80-9.

Downe-Wamboldt, B. 1992: Content analysis: method, applications, and issues. Health Care for Women International 13, 313-21.

Freed, G.L., Jones, T.M. and Fraley, J.K. 1991: Attitudes and education of pediatric house staff concerning breast-feeding. Southern Medical Journal 58, 483-5.

Hakulinen, T. 1998: The family dynamics of childbearing and childrearing families, related family demands and support received from child health clinics. Acta Universitatis Tamperensis 585. Tampere: University of Tampere.

Hickey, G. and Kipping, E. 1996: A multi-stage approach to the coding of the data from openended questions. Nurse Researcher 4, 81-91.

Higgins, B.S., Schilmoeller, G.L., Baranowski, M.D. and Coladarci, T.T. 1993: Support systems and caretaking behaviors of adolescent and older mothers: The first year after delivery. Journal of Child and Adolescent Psychiatric and Mental Health Nursing 6, 5-14.

Hillan, E. 1992: Issues in the delivery of midwifery care. Journal of Advanced Nursing 17, 274-8.

Jansson, A., Isacsson, Å., Kornfält, R. and Lindholm, L.H. 1998: Quality in child healthcare. The views of mothers and public health nurses. Scandinavian Journal of Caring Science 12, 195-204.

Karila, I. 1988: Vanhemmuuteen siirtyminen. Lapsivuodeajan psyykkisten vaikeuksien ennakointi I. [Transition to parenthood. Prediction of mental distress during puerperium I]. Jyväskylä: University of Jyväskylä, The Department of Psychology.

Karila, I. 1989: Siirtymä vanhemmuuteen. [Transition to parenthood]. Reports from the Department of Psychology, 304. Jyväskylä: University of Jyväskylä.

Kasch, C.R. 1986: Establishing a collaborative nurse-patient relationship: a distinct focus of nursing action in primary care. Image 18, 44-7.

Kuronen, M. 1993: Lapsen hyväksi naisten kesken: tutkimus äitiys- ja lastenneuvolan toimintakäytännöistä. Stakesin tutkimuksia: 35. Jyväskylä: Gummerus.

Lohiniva, V. 1998: Terveydenhoitajan työ ja kvalifikaatiot pohjoisessa ympäristössä. [The work and qualifications of public health nurse in the northern environment]. Acta Universitatis Ouluensis, D 509, Oulu: University of Oulu.

Mercer, R.T. 1986: First-time motherhood: Experiences from teens to forties. New York: Springer.

Paavilainen, E. and Åstedt-Kurki, P. 1997a: The client-nurse relationship as experienced by public health nurses: toward better collaboration. Public Health Nursing 14, 137-42.

Paavilainen, R. and Åstedt-Kurki, P. 1997b: Self-reported family health and well-being after discharge from maternity hospital: a phenomenological study. Journal of Advanced Nursing 26, 266-72. 
Payne, R.L. and Jones, J.G. 1987: Measurement and methodological issues on social support. In Kasl, S.V. and Cooper, C.L., editors, Stress and health: Issues in research methodology. New York: John Wiley, 167-205.

Pelkonen, M. 1994: Lapsiperheiden voimavarat ja niiden vahvistaminen hoitotyön keinoin. [Nursing Interventions Facilitating the Use of Family Resources in Primary Health Care]. Kuopio University Publications E. Social Sciences 18. Kuopio: University of Kuopio.

Perälä, M-L., Pelkonen, M., Vehviläinen-Julkunen, K., Viisainen, K. and Räikkönen, O. 1998: Äitiyshuollon palvelut muutoksessa. [Maternity clinic's services in change] In Sihvo, S. and Koponen, P., editors, Perhesuunnittelusta lisääntymistarpeeseen. Stakes Sosiaali-ja terveysalan tutkimus-ja kehittämiskeskus, raportteja 20: Gummerus.

Polit, D.F. and Hungler, B.P. 1999: Nursing research. Principles and methods, 6th edn. Philadelphia: Lippincott.

Pridham, K.F. 1984: Information needs and problem-solving behavior of parents of new babies. Birth Defects 20, 125-65.

Pridham, K.F. 1987: Meaning of infant feeding issues and mothers' use of help. Journal of Reproductive and Infant Psychology 5, 142-52.

Pridham, K.F. and Chang, A.S. 1992: Transition to being the mother of a new infant in the first 3 months: Maternal problemsolving and self-appraisals. Journal of Advanced Nursing 17, 204-16.

Pridham, K.F., Hanse, M.F., Bradley, M.E. and Heighway, S. 1982: Issues of concerns to mothers of new infants. Journal of Family Practice 14, 1079-85.

Rautava, P. 1989: Health Education in the Finnish Maternity Health Care System, Evaluation of Effectiveness. Publications of the National Board of Health. Series Original reports 14/1989. Turku: Grafia Oy.

Suomen Tilastollinen Vuosikirja 1995: [Statistical Yearbook of Finland]. Statistics Finland. Hämeenlinna: Karisto.

Tarkka, M-T. 1996: Äitiys ja sosiaalinen tuki. [Motherhood and social support]. Acta Universitatis Tamperensis, ser A vol. 518. Tampere: University of Tampere.

Tarkka, M-T. and Paunonen, M. 1996: Social support and its impact on mothers' experiences of childbirth. Journal of Advanced Nursing 23, 70-5.

Tarkka, M-T., Paunonen, M. and Laippala, P. 1998: What contributes to breast feeding success after childbirth in a maternity ward in Finland? Birth 5, 180-6.

Tarkka, M-T., Paunonen, M. and Laippala, P. 1999: Factors related to successful breast feeding by first-time mothers when the child is 3 months old. Journal of Advanced Nursing 29, 113-8.

Turner, R.J. 1983: Direct, indirect, and moderating effects of social support on psychological distress and associated conditions. In Caplan, H.B., editor, Psychosocial stress: Trends in theory and research, New York: Academic Press, 105-55.

Vehviläinen-Julkunen, K. 1990: Nursing in child health care: Maintaining awareness of the child's development and care. Publications of the University of Kuopio. Social Sciences. Original Reports 3/1990. Kuopio: University of Kuopio.

Vehviläinen-Julkunen, K. 1995: Health promotion in families with newborn children at home: clients' views. Social Sciences in Health: International Journal of Research and Practice 1, 3-13.

Ventura, J.N. 1986: Parent coping, a replication. Nursing Research 35, 77-80.

Viljanen, K. and Lauri, S. 1990: Perhekeskeisyys lastenneuvolatyössä. [Family-centred action at the child welfare clinic.] Lääkintöhallituksen julkaisuja 157, Helsinki.

Viljanen, K. 1993: Perhekeskeinen lastenneuvolatyö, käsiteanalyysi perhekeskeisyydestä. [Family-centred action at the child welfare clinic: a conceptual analysis of family-centredness.] Turun yliopisto.

Wilson, M.E., Hall, E.O. and White, M.A. 1994: Family dynamics and infant temperament in Danish families. Scandinavian Journal of Caring Sciences 8, 9-15. 